This item was submitted to Loughborough's Research Repository by the author.

Items in Figshare are protected by copyright, with all rights reserved, unless otherwise indicated.

\title{
The effect of conductive network on positive temperature coefficient behaviour in conductive polymer composites
}

\section{PLEASE CITE THE PUBLISHED VERSION}

https://doi.org/10.1016/j.compositesa.2020.106074

\section{PUBLISHER}

Elsevier

VERSION

AM (Accepted Manuscript)

\section{PUBLISHER STATEMENT}

This paper was accepted for publication in the journal Composites Part A: Applied Science and Manufacturing and the definitive published version is available at https://doi.org/10.1016/j.compositesa.2020.106074.

\section{LICENCE}

CC BY-NC-ND 4.0

\section{REPOSITORY RECORD}

Liu, Yi, Eric Asare, Harshit Porwal, Ettore Barbieri, Stergios Goutianos, Jamie Evans, Mark Newton, et al.. 2020. "The Effect of Conductive Network on Positive Temperature Coefficient Behaviour in Conductive Polymer Composites". Loughborough University. 


\title{
The Effect of Conductive Network on Positive Temperature Coefficient Behaviour in Conductive Polymer Composites
}

Yi Liu,,${ }^{\mathrm{a}, \mathrm{b}}{ }^{*}$ Eric Asare, ${ }^{\mathrm{a}}$ Harshit Porwal, ${ }^{\mathrm{d}}$ Ettore Barbieri, ${ }^{\mathrm{e}}$ Stergios Goutianos,${ }^{\mathrm{f}}$ Jamie Evans, ${ }^{\mathrm{d}}$

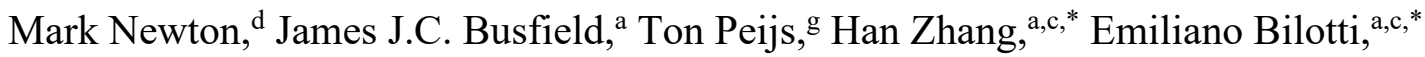

a. School of Engineering and Materials Science, Queen Mary University of London, Mile End Road, London E1 4NS, UK

b. Department of Materials, Loughborough University, Loughborough LE11 3TU, UK

c. Nanoforce Technology Ltd., Joseph Priestley Building, Queen Mary University of London, Mile End Road, London E1 4NS, UK

d. LMK Thermosafe Ltd., 9-10 Moonhall Business Park, Helions Bumpstead Rd, Haverhill, Suffolk CB9 7AA, UK

e. Japan Agency for Marine-Earth Science and Technology (JAMSTEC) Research Institute for Value-Added-Information Generation (VAiG) Center for Mathematical Science and Advanced Technology (MAT) 3173-25, Showa-machi, Kanazawa-ku, Yokohama-city, Kanagawa 236-0001, Japan

f. Department of Wind Energy, Section of Composite Mechanics and Structures, Technical University of Denmark, Risø Campus, DK-4000 Roskilde, Denmark g. Materials Engineering Centre, WMG, University of Warwick, Coventry, CV4 7AL, UK

Corresponding email: y.liu2@,lboro.ac.uk; han.zhang@qmul.ac.uk; e.bilotti@qmul.ac.uk

\begin{abstract}
Flexible and controllable self-regulating heating devices with positive temperature coefficient (PTC) behaviour are potentially excellent candidates in applications like healthcare, soft
\end{abstract}


robotics, artificial skin and wearable electronics. Although extensive studies have been carried out in this field to understand the mechanism of PTC effect, rather limited conclusions have been reached. Many controversies remain on the dominating factors that influence the PTC performance of composites, hence limiting their design and broader applications. Herein, we propose a systematic study to explore the PTC phenomenon and the underlying mechanism, from a conductive network viewpoint, taking account of both conductive fillers and polymer matrices. Three representative conductive fillers with distinct dimensions and shapes (0D silver coated glass sphere, 1D carbon nanotubes and 2D graphene nanoplatelets), in combination with three different polymer matrices (high density polyethylene, thermoplastic polyurethane and polycarbonate) were selected to elucidate the effect of the "robustness" of different conductive networks on PTC behaviour in conductive polymer composites (CPCs). The desired conductive network can be obtained by selecting preferentially larger filler size, lower filler aspect ratio and/or selective distribution of filler (e.g. in the amorphous region of semi-crystalline polymers). The highest PTC intensity was observed around the "critical" percolation threshold, in correspondence of networks with the lowest number of inter-particle contacts. This study can serve as a guideline in the selection of the most appropriate conductive filler and polymer matrix for various self-regulating heating requirements and final applications.

Keywords: Nanocomposites; Pyroresitivity; Positive temperature coefficient; Electrical conductivity; Graphene nanoplatelets; Carbon nanotubes.

\section{Introduction}

With the rapid development of functional and intelligent devices, there is an increasing demand for technological progress on new materials and devices, which can respond to external stimuli spontaneously. Benefiting from a large variety of polymer matrices and conductive fillers 
available, conductive polymer composites (CPCs) can be easily fabricated with desired properties, fulfilling a broad spectrum of requirements in various applications. By combining different polymer matrices and conductive fillers, not only the electrical and mechanical properties of CPCs can be tuned and tailored to specific target requirements, but other functionalities can also be introduced such as sensitivity to a number of external stimuli including strain [1-3], humidity [4], temperature [5-7], liquid [8] and damage [9-11].

Certain CPCs, in particular, can show a pyroresistive behaviour ("pyro" is a Greek word meaning "fire/heat"), with their electrical resistivity changing with temperature. Pyroresistivity can manifest in two ways: (i) an increase in electrical resistivity with increasing temperature known as positive temperature coefficient (PTC) effect - and (ii) a decrease in electrical resistivity with increasing temperature - known as negative temperature coefficient (NTC) effect $[12,13]$. PTC effect in most cases refers to a switching type transition, where the resistivity of the polymer nanocomposite changes by several orders of magnitude at the critical temperature. The change in resistivity is defined by the PTC intensity, which is quantified as the maximum resistivity $\left(\rho_{\max }\right)$ over the room temperature resistivity $\left(\rho_{R T}\right)$. Although many researchers have dedicated efforts in this field and in studying this physical phenomenon, up until now, the underlying mechanism of the PTC effect is still not well understood [14]. Conflicting explanations have been proposed and systematic and direct supporting evidence for this critical phenomenon is still insufficient.

Different hypotheses on the factors dominating the PTC effect have been proposed, based on experimental observations from different systems, some showing evident inconsistencies. For instance, some researchers in early studies found that the polymer crystalline phase change with temperature has a strong influence on the electrical conductivity of CPCs $[15,16]$. Luo et al. investigated composites based on carbon black (CB) and polymers with different degree of crystallinity; from high to low, high density polyethylene (HDPE), low density polyethylene 
(LDPE), LDPE/ethylene-vinyl acetate (EVA) blends and amorphous polymethylmethacrylate (PMMA). The results have showed a correlation between polymer crystallinity and PTC intensity, namely the higher the crystallinity the higher the PTC intensity. Amorphous PMMA/CB composites showed the smallest PTC intensity, usually below one order of magnitude [15]. This finding is in agreement with the work on CB-based polymer composites by Meyer in early 1970s [17]. Thermal volume expansion is phenomenologically one of the leading factors for the polymeric PTC transition, as reported by Yi et al. for HDPE/CB systems [18]. In semicrystalline polymers, the change of crystallites to an amorphous melt around the melting temperature leads a step change in volume expansion and an increase in the coefficient of thermal expansion (CTE). No such step change occurs instead in an amorphous polymer. However, although polymer crystallinity has been widely believed to be a dominant factor for the PTC effect, contrasting results have also been reported from literature, in which no correlation between PTC intensity and crystallinity was found [19, 20]. For example, a surprisingly large PTC intensity (five orders of magnitude) has been reported for an amorphous CPC system based on PMMA containing 40 wt.\% Ag coated glass beads by Kar et al. [21]. The same group reported a three orders of magnitude change in resistance in a nickel coated graphite (40 wt.\%) filled polycarbonate (PC). Xiong et al. has reported that a CB filled amorphous polyurethane (PU) can have a PTC intensity of three orders of magnitude by adding reactive low molecular crystals stearic acid as crystalline phase into amorphous polymers [19]. Overall, it is understandable and reasonable to believe that although the polymer matrix crystallinity has a significant influence on the PTC effect, other factors such as filler size and topology might also play a role, and in some cases a more dominant one.

Many researchers have revealed that CPCs with larger average filler size exhibit a higher PTC intensity and higher resistivity at room temperature than those systems with smaller filler size at similar filler content, possibly linked to the increase of average interparticle distance with 
increasing particle size $[22,23]$. The effect of different filler content and the use of a combination of different conductive fillers were shown to have an even more complex influence on the PTC effect [24]. It is believed that the PTC behaviour of conductive composites relies on the "robustness" of the conductive network formed within the polymer matrix $[25,26]$. Therefore, the conductive network in the CPCs can be considered the real dominating factor that influences the PTC effect, containing effects from both filler and matrix. Unfortunately, to date, a comprehensive study of the effect of the matrix, the filler and its formed conductive network on the PTC effect is still lacking.

Herein, an investigation into the understanding of how the conductive network affects the PTC behaviour has been performed. The contributions and influences of different types of filler and polymer matrix on the PTC performance are considered, exploring effects arising from the use of conductive fillers with different shapes and dimensions as well as different polymer matrices. Three classes of conductive fillers with distinct dimensional features have been employed in this work, ranging from spherical zero-dimensional (0D) silver coated glass spheres (AgS), 1dimensional (1D) carbon nanotubes (CNT), and 2-dimensional (2D) graphite nanoplates (GNP) [27]. The motivation behind this selection is to explore the influence of dimensionality of the fillers on the electrical properties of the composites, the different conductive networks formed and their subsequent pyroresistive behaviour. In addition, three representative polymer matrices with distinct structure and properties have been selected: high density polyethylene (HDPE), thermoplastic polyurethane (TPU) and polycarbonate (PC). HDPE is a typical semicrystalline polymer widely used for PTC materials, while TPU is a thermoplastic elastomer for flexible applications, with the presence of hard blocks, acting as physical crosslinks upon crystallisation. PC is a typical amorphous engineering polymer with outstanding strength, and impact resistance. With this systematic and comprehensive study, the factors that affect the pyroresistive (both PTC and NTC) behaviours as well as their underlying 
mechanisms are explored, providing a material selection guideline for self-regulating heating applications in the fields like healthcare, robotics, and smart heater.

\section{Experimental}

\section{Materials}

The materials used in this study are listed in Table 1. All the polymers are in the form of pellets and dried overnight at $80^{\circ} \mathrm{C}$ before compounding.

Table 1. Information on polymers and conductive fillers used in this study.

\begin{tabular}{|c|c|c|c|}
\hline & Materials & Trade name & Information \\
\hline \multirow{3}{*}{ Polymer } & $\begin{array}{l}\text { Thermoplastic polyurethane } \\
\text { (TPU) }\end{array}$ & Lubrizol Estane $^{\circledR} 58437$ & Density $1.19 \mathrm{~g} / \mathrm{cm}^{3}$ \\
\hline & $\begin{array}{l}\text { High density polyethylene } \\
\text { (HDPE) }\end{array}$ & Rigidex ${ }^{\circledR}$ HD5218EA & Density $0.95 \mathrm{~g} / \mathrm{cm}^{3}$ \\
\hline & Polycarbonate (PC) & $\begin{array}{l}\text { Bayer Material Science } \\
\text { Makrolon } 2805\end{array}$ & Density $1.20 \mathrm{~g} / \mathrm{cm}^{3}$ \\
\hline \multirow{3}{*}{$\begin{array}{l}\text { Conductive } \\
\text { filler }\end{array}$} & $\begin{array}{l}\text { Multi-wall carbon nanotubes } \\
\text { (MWCNTs) }\end{array}$ & Nanocyl $^{\circledR} \mathrm{NC} \mathrm{N000}{ }^{\mathrm{TM}}$ & $\begin{array}{l}\text { Average diameter of } 9.5 \mathrm{~nm}, \\
\text { carbon purity } 90 \%[28]\end{array}$ \\
\hline & $\begin{array}{l}\text { Silver coated glass spheres } \\
(\mathrm{AgS})\end{array}$ & Potters Industries Ltd. & $\begin{array}{l}\text { Average diameter of } 2.5 \mu \mathrm{m}, 50 \\
\mu \mathrm{m}, 100 \mu \mathrm{m} \text { with the density of } \\
\text { around } 3.6,2.6 \text { and } 2.5 \mathrm{~g} / \mathrm{cm}^{3} \text {, } \\
\text { respectively }\end{array}$ \\
\hline & Graphite nanoplates (GNPs) & $\mathrm{xGnP}^{\circledR}$ Grade $\mathrm{M}$ & $\begin{array}{l}\text { Average particle diameters of } 15 \\
\mu \mathrm{m} \text {, density } 2.2 \mathrm{~g} / \mathrm{cm}^{3} \text {, carbon } \\
\text { content }>99.5 \%\end{array}$ \\
\hline
\end{tabular}

\section{Fabrication of composites}

A Collin Lab twin-screw compounder $\mathrm{P}(\mathrm{ZK} 25,25 \mathrm{~mm}, \mathrm{~L} / \mathrm{D}=40)$ was used to produce masterbatches of TPU with 5 wt.\% CNT and of HDPE with 24 wt.\% GNP. Extruder throughput was $2 \mathrm{~kg} / \mathrm{h}$ using a screw speed of $50 \mathrm{rpm}$ and $220 \mathrm{rpm}$ for CNT and GNP, respectively, with a temperature profile ranging from $190{ }^{\circ} \mathrm{C}$ to $240{ }^{\circ} \mathrm{C}$, over 8 heating zones [29]. Apart from the masterbatches, the remaining compounds and diluted composites from the masterbatches were prepared by melt mixing using a DSM X'plore MC 15 micro-compounder (Netherland). 
Both HDPE and TPU based composites were melt compounded at $200{ }^{\circ} \mathrm{C}$ using a screw speed of $50 \mathrm{rpm}$ for $5 \mathrm{~min}$ in nitrogen atmospheres, while PC based composites were processed at a temperature of $280{ }^{\circ} \mathrm{C}$. The composites prepared in this study are listed in Table 2 . The extruded strands were chopped into pellets and subsequently compression moulded into rectangular shaped samples with dimensions of $30 \times 10 \times 2 \mathrm{~mm}$, using a Collin hot press P300E, at $220^{\circ} \mathrm{C}$ for $5 \mathrm{~min}$ under 60 bar pressure. Two pieces of copper mesh $(0.16 \mathrm{~mm}$ aperture wire diameter) were embedded at mid-depth and on both sides of each specimen during compression moulding and used as the electrodes for all electrical characterisations.

Table 2 List of composite systems.

\begin{tabular}{ccc}
\hline HDPE based composites & TPU based composites & PC based composites \\
\hline HDPE/AgS & TPU/AgS & PC/AgS \\
$(2.5 \mu \mathrm{m}, 50 \mu \mathrm{m}$, and $100 \mu \mathrm{m})$ & $(2.5 \mu \mathrm{m}, 50 \mu \mathrm{m}$, and $100 \mu \mathrm{m})$ & $(2.5 \mu \mathrm{m}, 50 \mu \mathrm{m}$, and $100 \mu \mathrm{m})$ \\
\hline HDPE/GNP & TPU/GNP & - \\
\hline HDPE/CNT & TPU/CNT \\
\hline
\end{tabular}

\section{Characterisation}

Scanning electron microscopy (FEI Inspector-F, Netherlands) was used to observe the morphology of as-received materials, as well as the fabricated conductive composite specimens. Filler size distributions of as-received silver coated glass spheres were characterised by SEM imaging, after having deposited the spheres on a conductive substrate (SI Figure 1, see Supporting Information). All the morphologies of CPCs in this research were observed on cryofractured surfaces, which were induced by immersing the specimens into liquid nitrogen for 10 min before fracture to expose the internal microstructure. All the surfaces analysed were gold sputtered before imaging. The images were taken at different magnifications with an accelerating voltage of $20 \mathrm{kV}$. 
Thermal analysis of the samples was performed using differential scanning calorimetry (DSC) (DSC4000, PerkinElmer, Massachusetts, USA). All samples were heated from $20^{\circ} \mathrm{C}$ to $200{ }^{\circ} \mathrm{C}$ at $10{ }^{\circ} \mathrm{C} / \mathrm{min}$ under nitrogen atmosphere and then cooled back to room temperature (RT) at the same rate, for two heating cycles. The second heating curve was used in examining the melting behaviour of the composite to eliminate differences in thermal history.

Dynamic mechanical analysis (DMA) was performed on a TA Instruments DMA Q800 machine (USA), equipped with a fixture for three-point bending. A frequency of $1 \mathrm{~Hz}$, a strain of $1 \%$ and a heating rate of $3{ }^{\circ} \mathrm{C} / \mathrm{min}$, between $-150{ }^{\circ} \mathrm{C}$ to $100{ }^{\circ} \mathrm{C}$, were chosen for these tests. The samples were compression moulded into rectangular bars with the dimensions of $30 \times 10$ $\times 2 \mathrm{~mm}$.

Electrical resistance was measured by the two-point probe technique and used to calculate the electrical resistivity, obtained using a picoammeter (Keithley 6485, USA) and a DC voltage source (Agilent HP 6614C, USA). As the electrodes are embedded into the compression moulded CPC, the contact resistance between the materials and electrodes are consistent and relatively low.

The pyroresistive behaviour of all samples was tested with an apparatus consisting of a temperature-controlled oven (heating rate of $2{ }^{\circ} \mathrm{C} / \mathrm{min}$ ) and an in-situ two-point resistance measurement unit, obtained by combining a picoammeter (Keithley 6485, USA) with a DC voltage source (Agilent HP 6614C, USA). A thermocouple was placed close to, but not touching, the specimen to ensure reliable temperature reading. A constant voltage $(1 \mathrm{~V})$ was applied during heating and cooling cycles on the rectangular samples $(30 \times 10 \times 2 \mathrm{~mm})$, while the current and temperature were monitored and recorded simultaneously. Since the size difference induced by thermal expansion of the matrix during heating is very small compared to the sample dimension, it has been neglected from the electrical resistivity calculation. 
Voltage was applied with 1 second on/off intervals, to avoid electric field-induced filler alignment and network alteration. A minimum of three samples was tested for all characterisations.

\section{Results and discussion}

Morphology

It is essential to investigate the microstructure of the composites in order to obtain a better understanding of the conductive networks formed within the polymer matrices and their influence on the electrical and pyroresistive properties of CPCs. Figure 1a-e shows the micrographs of as-received fillers of different size $(\mathrm{AgS} 2.5 \mu \mathrm{m}, 50 \mu \mathrm{m}$, and $100 \mu \mathrm{m})$ and shape (AgS as spherical 0D filler, CNT as 1D filler and GNP as 2D filler). The size distributions of $\mathrm{AgS}$ are summarised in Supporting Information (SI Figure 1). 

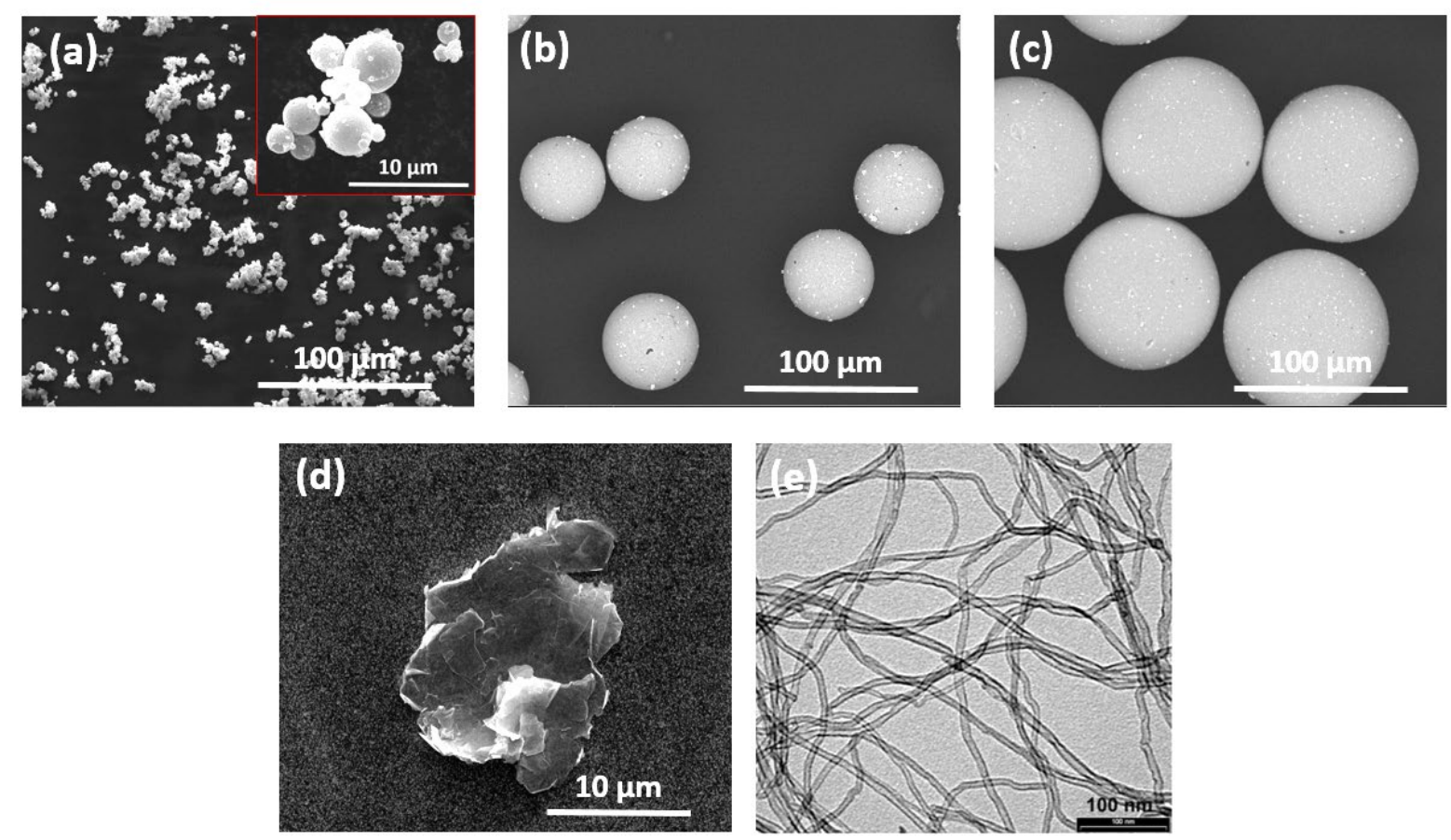

Figure 1. SEM micrographs of conductive fillers: (a) $2.5 \mu \mathrm{m} \mathrm{AgS;} \mathrm{(b)} 50 \mu \mathrm{m} \mathrm{AgS;} \mathrm{(c)} 100 \mu \mathrm{m}$ AgS; (d) GNP, and transmission electron microscopy (TEM) image of (e) CNT [28].

In order to understand the effect of filler size on the microstructure of the composite and any preferential distribution of conductive fillers within the matrix, AgS fillers with distinctly different diameters $(2.5 \mu \mathrm{m}, 50 \mu \mathrm{m}$, and $100 \mu \mathrm{m})$ were selected. Figure 2 shows images of PC based composites containing $2.5 \mu \mathrm{m}, 50 \mu \mathrm{m}$, and $100 \mu \mathrm{m} \mathrm{AgS}$, respectively. The dispersion of up to 30 wt. $\% / 12.5$ vol.\% (above percolation) of $2.5 \mu \mathrm{m} \mathrm{AgS} \mathrm{dispersed} \mathrm{in} \mathrm{PC} \mathrm{matrix} \mathrm{is}$ generally rather uniform (Figure 2b), with the exception of some more concentrated regions (red circles in Figure 2a). Figure 2c-d show the morphologies of PC composites containing 40 $\mathrm{wt} \% / 24.2$ vol.\% loading $50 \mu \mathrm{m} \mathrm{AgS} \mathrm{(above} \mathrm{percolation)} \mathrm{and} 40 \mathrm{wt} \% / 24.2$ vol.\% loading (below percolation) of $100 \mu \mathrm{m} \mathrm{AgS}$, respectively. It is worth noting that, for the same filler concentration in a given volume of composite, smaller sized fillers (i.e. $50 \mu \mathrm{m}$ ) are present in larger numbers compared to larger fillers (i.e. $100 \mu \mathrm{m}$ ). This also implies that smaller (spherical) 
fillers present a higher specific surface area, with more potential contact points (or points close enough for tunnelling) between fillers to form conductive pathways (Figure 2c), as compared to larger spherical fillers (Figure 2d). This difference in the number of contact points is believed to have a significant impact on the electrical properties of the CPCs.
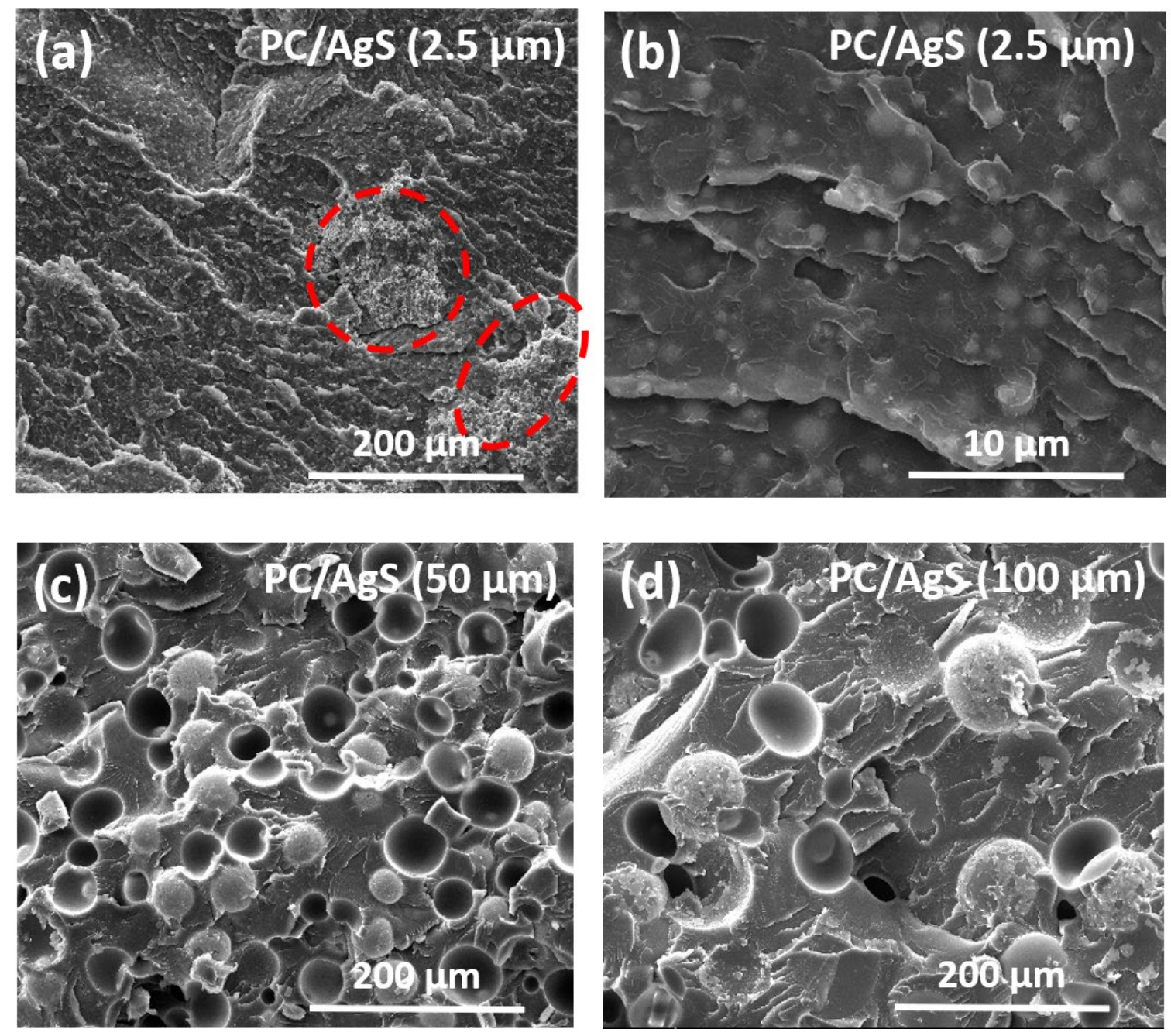

Figure 2. SEM images of cold-fractured cross-sectional areas of PC based composites containing $30 \mathrm{wt} . \%$ (above percolation) of $2.5 \mu \mathrm{m} \mathrm{AgS}$, at a magnification of (a) 500x and (b) 2000x; (c) 40 wt.\% (above percolation) of $50 \mu \mathrm{m} \mathrm{AgS,} \mathrm{showing} \mathrm{several} \mathrm{contact} \mathrm{points} \mathrm{between}$ fillers; and (d) 40 wt.\% (below percolation) of $100 \mu \mathrm{m} \mathrm{AgS,} \mathrm{without} \mathrm{obvious} \mathrm{contact} \mathrm{points}$ between fillers. 
As mentioned earlier, filler shape can also greatly affect the conductive network and hence the subsequent PTC behaviour of the composite. The effect of filler shape has been explored with representative fillers (distinct aspect ratio) from $0 \mathrm{D}$ to $2 \mathrm{D}$ in TPU matrix: $40 \mathrm{wt}$. $\%$ of $\mathrm{AgS}$ as 0D filler $(50 \mu \mathrm{m}), 15 \mathrm{wt} . \%$ of GNP as 2D filler and $3 \mathrm{wt} . \%$ of CNT as 1D filler, respectively, as shown in Figure 3a-c. The filler loading was chosen based on the respective percolation threshold: 40 wt.\% for AgS, 15 wt.\% for GNP and 3 wt.\% for CNT, which are all just above each of their corresponding percolation thresholds in TPU matrix (percolation thresholds have been presented in Figure 5 and SI Figure 3). SEM images reveal that the number of contact points between the AgS fillers is rather limited (Figure 3a), compared to GNPs where a larger number of contact points and a more easily formed percolated network can be expected (Figure 3b). This difference between $0 \mathrm{D} \mathrm{AgS}$ and 2D GNPs is believed to be due to their different aspect ratios, where a higher aspect ratio is generally desired for electrical conductivities as the percolation threshold is lower. Figure $3 \mathrm{c}$ shows a rather uniform dispersion within the TPU matrix, consistent with our previous findings [30]. The shape, size and high aspect ratio of CNTs allow the formation of an even more robust network, with a larger number of contact points at a relatively low volume fraction [16]. 

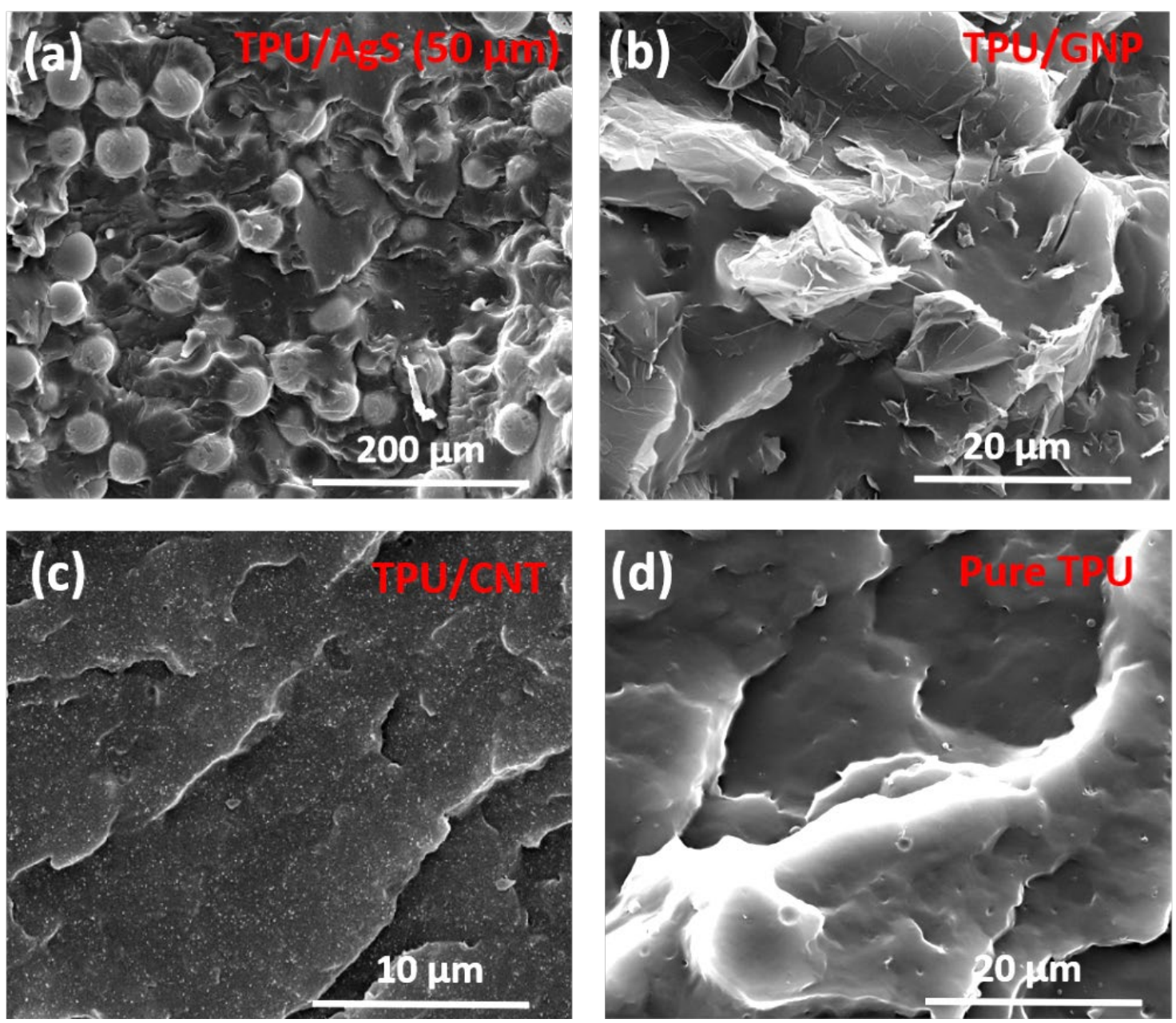

Figure 3. SEM images of the cold-fractured cross-sectional area of TPU based composites containing (a) 40 wt. \% of AgS as OD filler (50 $\mu \mathrm{m})$; (b) 15 wt.\% of GNP as 2D filler; (c) 3 wt.\% of CNT as $1 D$ filler, showing a clear positive relationship between the number of contact points and filler aspect ratios; (d) unfilled TPU as reference.

Apart from the influence of filler size and shape on the conductive network formed, the effect of the polymer matrix has also been explored. Figure 4 shows SEM images of HDPE, TPU and PC composites containing the same amount of $50 \mu \mathrm{m}$ AgS. HDPE shows the worst interfacial bonding between filler and matrix while TPU shows the best. This finding is believed to be due to a combined effect of several intrinsic polymer properties, including wetting and surface tension (PC $>$ TPU $>$ HDPE) [31], ductility of the polymer matrix (TPU $>$ HDPE $>$ PC) and thermal 
contraction coefficient upon cooling (HDPE $>$ PC) [32]. There is no significant difference in filler distribution between the three polymer matrices, although the AgS in TPU and PC are slightly more homogenously distributed than in HDPE. In HDPE composites, some polymer rich areas can be found, which are believed to be associate with the semicrystalline and apolar nature of the polymer generating inhomogeneity in filler dispersion $[15,33]$. The location of the spheres as well as cavities (left after debonding of the AgS particle) are all marked with coloured circles to highlight the distribution of the $\mathrm{AgS}$ within the polymer matrix.
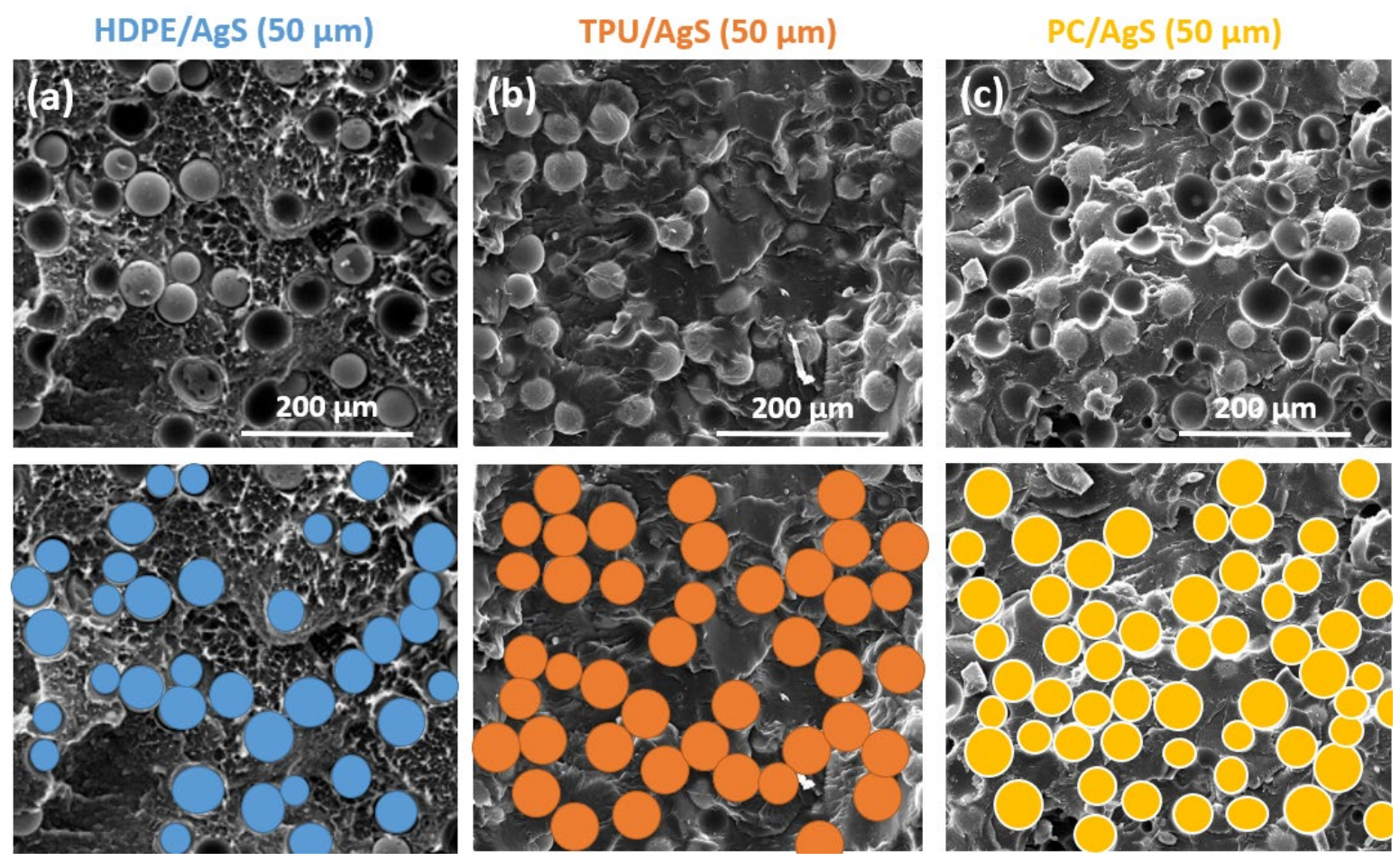

Figure 4. SEM images of cold-fractured cross-sectional areas of $40 \mathrm{wt} \%$ of $50 \mu \mathrm{m} \mathrm{AgS} \mathrm{filled}$ (a) HPDE; (b) TPU; and (c) PC. The coloured circles indicate the locations of the AgS particles in the polymer matrix.

Although no distinct difference in conductive filler networks was observed for this $50 \mu \mathrm{m} \mathrm{AgS}$ filled HPDE, TPU, PC matrices, due to the large size of the filler, it is expected that the nature of the host polymer can in general play an important role in the PTC effect. Therefore, the 
intrinsic polymer properties have been characterised and analysed here. The variation of storage modulus of the polymer matrix with temperature is one of the potentially important physical properties (see SI Figure 2a-b). The degree of crystallinity is another one. The relatively high crystalline content of HDPE (about $57 \%$ crystalline phase melting at a $T_{\mathrm{m}}$ of around $130{ }^{\circ} \mathrm{C}$ ) is expected to result in the selective distribution of filler in the amorphous phase only. On the contrary, TPU and PC are two amorphous polymers (see in SI Figure 2c). The characterisation on the main physical properties of the polymer matrices is important as it establishes a baseline for better understanding the PTC behaviour.

\section{Electrical and pyroresistive properties of AgS particles of different sizes in HDPE, TPU} and PC

Figure 5a-c show the electrical conductivity of HDPE, TPU, PC composites containing AgS $(2.5 \mu \mathrm{m}, 50 \mu \mathrm{m}$ and $100 \mu \mathrm{m})$, as a function of filler content. All the percolation curves show a very sharp "on-off” behaviour, going from a not measurable value of electrical conductivity to a maximum plateau above a specific AgS filler loading. This is in accordance with studies by Ambrosetti et al, who observed that a sharp cut-off applies to CPCs made of large conducting particles [34].

Figure $5 \mathrm{~d}$ summaries the percolation threshold values of each composite system. It shows a clear increasing trend of percolation threshold values with increasing $\mathrm{AgS}$ filler dimensions, which is attributed to the decrease of their specific surface areas, as suggested by many researchers $[35,36]$. Clearly, with a smaller filler dimension, a higher surface area and hence a larger number of connecting pathways can be expected, resulting in a more "robust" conductive network compared to fillers with the same loading but larger dimensions. The obtained percolation thresholds of HDPE/AgS composites with $2.5 \mu \mathrm{m}, 50 \mu \mathrm{m}$ and $100 \mu \mathrm{m}$ filler dimension are 5.5 vol. $\%, 16.9$ vol.\% and 18.9 vol.\%, respectively. A similar trend is 
observed in TPU/AgS and PC/AgS composites, where filler dimensions of $2.5 \mu \mathrm{m}, 50 \mu \mathrm{m}$ and $100 \mu \mathrm{m}$ give the percolation thresholds of 9.9 vol. $\%, 24.0$ vol. $\%$ and 28.0 vol. $\%$ for TPU and 12.5 vol. $\%, 24.2$ vol. $\%$ and 28.2 vol. $\%$, respectively. These findings are consistent with earlier morphological observations, where a higher number of contact points between fillers was observed for smaller sized filler.

Regarding the three different polymer matrices, it can be noted that HDPE has the lowest percolation thresholds. This is believed to be due to their semicrystalline nature, which leads to high effective concentration of filler in the amorphous phase (consequence of exclusion from the crystalline phase), and hence a lower overall percolation threshold. For instance, the 2.5 $\mu \mathrm{m}$ AgS filled HDPE composites show a percolation threshold of around $5.5 \mathrm{vol} . \%$, which is approximately half the percolation threshold of TPU and PC (around 9.9 and 12.5 vol.\%). This is in agreement with the amount of crystalline phase in HDPE, which is $57.5 \%$ calculated from DSC measurement (see SI Figure 2c). For larger fillers dimensions $(50 \mu \mathrm{m}, 100 \mu \mathrm{m})$, which are much larger than the size of the crystalline domains, considerably lower percolation thresholds were observed in semi-crystalline HDPE than the other amorphous systems, although this was not as obvious as for the $2.5 \mu \mathrm{m}$ filler system. 

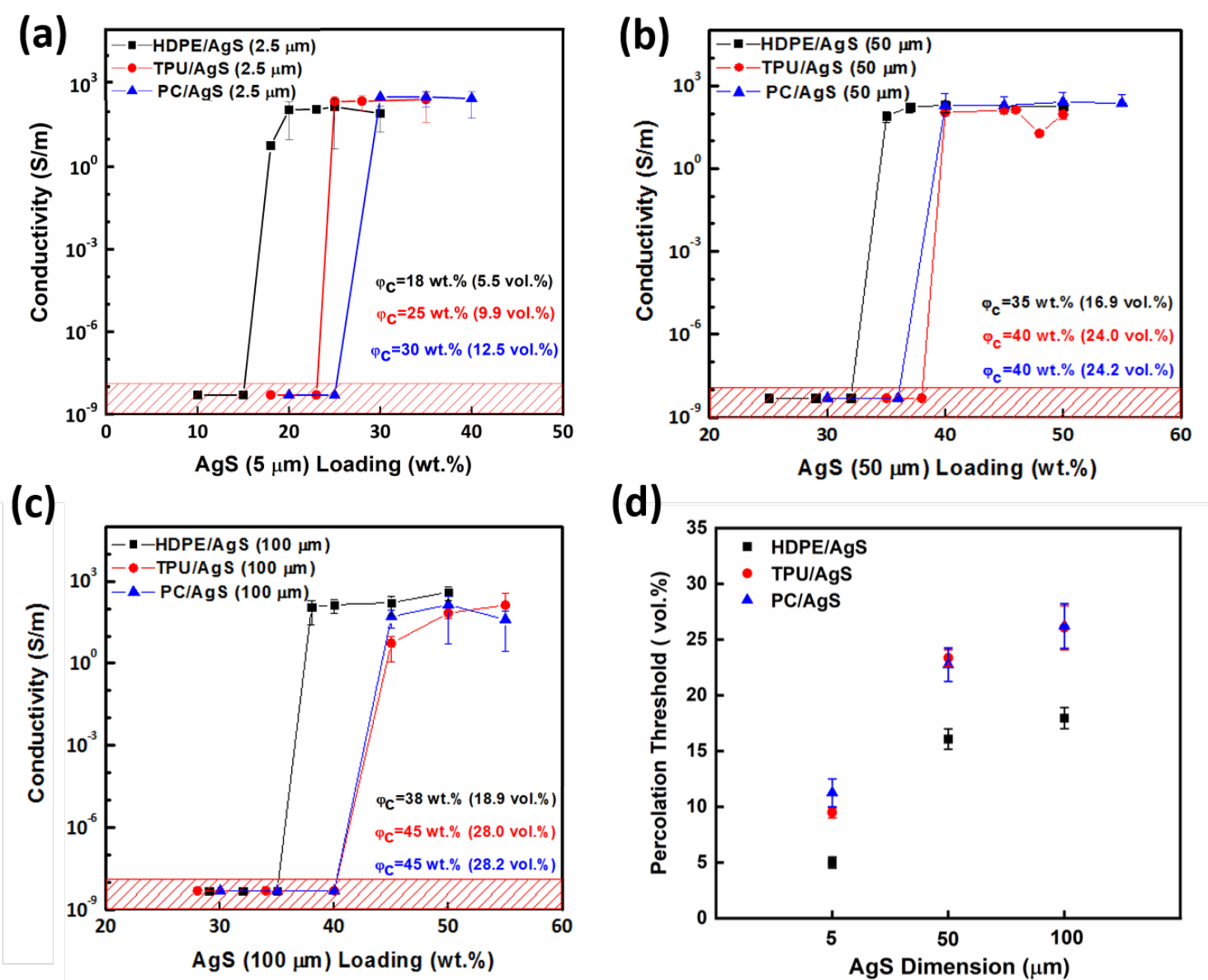

Figure 5. Electrical percolation curves of HDPE, TPU, and PC filled with (a) $2.5 \mu \mathrm{m} \mathrm{AgS;} \mathrm{(b)}$ $50 \mu \mathrm{m} \mathrm{AgS;}$; (c) $100 \mu \mathrm{m} \mathrm{AgS;} \mathrm{and} \mathrm{(d)} \mathrm{percolation} \mathrm{threshold} \mathrm{values} \mathrm{(in} \mathrm{volume} \mathrm{fraction)} \mathrm{of} \mathrm{the}$ three types of composites, error bars indicate the possible range of percolation threshold. The shaded area indicates the non-measurable electrical conductivity range.

To examine the pyroresistive behaviour of $\mathrm{AgS}(2.5 \mu \mathrm{m}, 50 \mu \mathrm{m}$ and $100 \mu \mathrm{m})$ filled HDPE, TPU and PC composites, the electrical resistivity of the composites was monitored as a function of temperature (Figure 6). The effect of both polymer matrix and filler size on the observed pyroresistive behaviour have been studied, in order to establish a systematic understanding of their influence on PTC behaviour. Figure 6a-c compares the effect of different polymer matrices with the same filler, while Figure 6d-f compares the effect of varying filler sizes in the same polymer matrix. 
As shown in Figure 6a, $\operatorname{AgS}(2.5 \mu \mathrm{m})$ based composites exhibit a relatively small PTC intensity, regardless of the polymer matrix. Among the three composites, HDPE/2.5 $\mu \mathrm{m} \mathrm{AgS} \mathrm{(25} \mathrm{wt. \% )}$ shows the highest PTC intensity (about two orders of magnitude), more than one order of magnitude higher than for TPU and PC based AgS $(2.5 \mu \mathrm{m})$ composites. This difference is attributed to polymer crystallinity and the greater thermal expansion associated with the melting of the crystal phase. However, as known from the morphological study, small-sized $\mathrm{AgS}(2.5 \mu \mathrm{m})$ with a larger number of contact points build more robust conductive networks, which are more difficult to disrupt under the effect of the matrix thermal expansion. This explains, phenomenologically, why the PTC intensity of HDPE/AgS $(2.5 \mu \mathrm{m})$ composite is much lower than the PTC intensity of HDPE composites containing larger AgS spheres (50, $100 \mu \mathrm{m})$. The same is true for the other polymer matrices. All the $50 \mu \mathrm{m}$ and $100 \mu \mathrm{m} \mathrm{AgS}$ based composites, independently on the polymer matrix (HDPE, TPU, and PC), show a very high PTC intensity, of about eight orders of magnitude (Figure $6 \mathrm{~b}$ and c). It is suggested that spherical conductive fillers of large size can induce a high PTC intensity as the number of conductive filler contact points is limited, which makes the conductive network more sensitive to perturbations, regardless of the polymer matrix. This is consistent with previous studies by our group and the concept of "robustness" of the conductive filler network [25]. The smaller the filler size, the more "robust" the conductive network is, as the number of specific conductive pathways increases, and the more difficult it is for the conductive network to be disrupted. However, the PTC intensity is not a monotonic function of filler size. In fact, the PTC behaviour of composites based on the $50 \mu \mathrm{m}$ and $100 \mu \mathrm{m} \mathrm{AgS}$ is very similar.

For what concerns the switching temperature, it can be observed that this is associated with a main phase transition of the polymer matrix (melting, softening, and/or glass transition temperature). For examples, the switching temperature of HDPE based composites shows a switching temperature around $130{ }^{\circ} \mathrm{C}$, which is in the proximity of the melting temperature of 
HDPE (129.8 ${ }^{\circ} \mathrm{C}$ from the DSC curve). The switching temperature of TPU based composites corresponds to the Vicat softening temperature of TPU $\left(90-100^{\circ} \mathrm{C}\right)$ [37]. While the switching temperature of $\mathrm{PC}$ based composites is above $140{ }^{\circ} \mathrm{C}$, close to the glass transition temperature of PC. The switching temperature of amorphous polymer-based systems seems slightly higher than the corresponding polymer phase transition temperature. This is believed to be related to the absence of a step change in specific volume, with only a slope change in TEC with temperature at around $T_{g}$. Overall, all the composites based on $50 \mu \mathrm{m}$ and $100 \mu \mathrm{m} \mathrm{AgS}$ are attractive pyroresistive materials and exploitable in self-regulating heating devices.

With the aim of having a tailored performance to suit various applications, the three different polymer matrices (HDPE, TPU and PC) can be considered as model systems with distinct switching temperatures and mechanical properties, which can be used to tailor the performance of the device to suit various applications. 

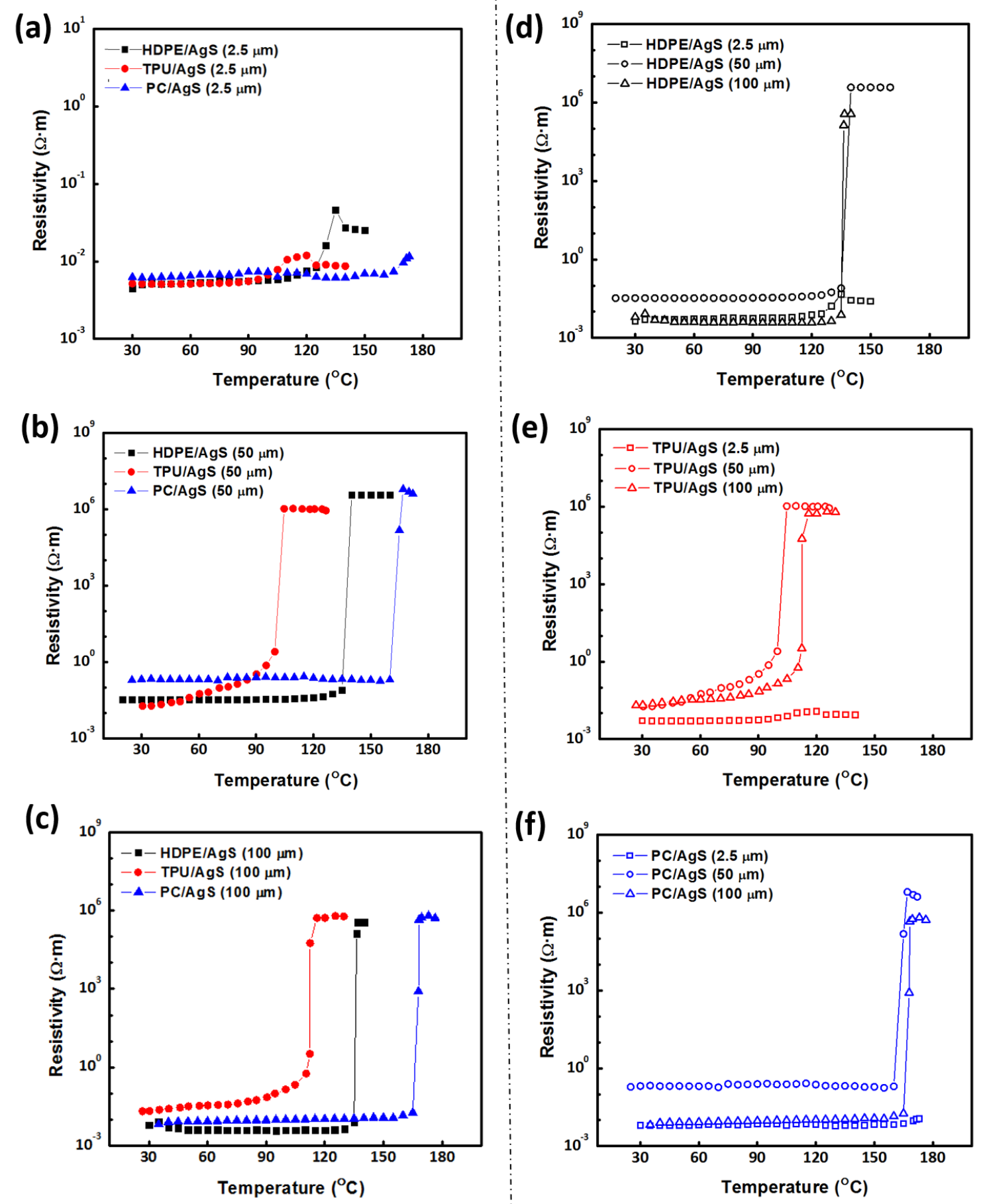

Figure 6. The pyroresistive behaviour of HDPE, TPU and PC filled with (a) $2.5 \mu \mathrm{m} \mathrm{AgS} \mathrm{(25}$ wt.\%, $30 w t . \%$ and 35 wt.\%); (b) $50 \mu m \operatorname{AgS~(50wt.\% );~and~(c)~} 100 \mu m \operatorname{AgS}(50 w t . \%)$. 
Pyroresistive behaviour of $2.5 \mu \mathrm{m}, 50 \mu \mathrm{m}$ and $100 \mu \mathrm{m}$ AgS filled composites in the matrix of

(d) HDPE, (e) TPU and (f) PC.

\section{Electrical and pyroresistive properties of GNP and CNT in HDPE and TPU}

Apart from 0D AgS, the other two fillers, 1D CNTs and 2D GNPs, are also investigated in order to examine the effect of filler shape on pyroresistive behaviour.

As expected, much lower percolation thresholds were found for HDPE composites containing GNPs and CNTs, with values of 8.8 wt.\% (4.0 vol.\%) and 1.67 wt.\% (1.0 vol.\%) for these two fillers, respectively (see SI Figure 2), due to their much larger aspect ratios as compared to 0D $\mathrm{AgS}$ microsized fillers. It is worth noting that dispersed GNPs are not necessarily completely rigid and flat when dispersed in a polymer matrix, while they are prone to folding and wrinkling during the melt compounding in addition to breaking (probably the main effect) [38], which reduces its effective aspect ratio and in turn affects the percolation threshold. This morphological feature of GNPs also has a significant impact on their formed conductive networks, and the subsequent pyroresistive properties of the corresponding composites.

The pyroresistive behaviour of both HDPE/GNP composites and HDPE/CNT composites are shown in Figure 7a-b, with three different filler concentrations for both systems to understand better the effect of the conductive network on their PTC behaviours.

HDPE/GNP composites (Figure 7a) at filler loadings of 18, 22, and 24 wt.\% show a similar trend of pyroresistive properties, with an increase of resistivity at around $130{ }^{\circ} \mathrm{C}$ for all three loadings. With decreasing GNP filler content, both the initial resistivity and the PTC intensity of the HDPE/GNP composites increase due to their less "robust" conductive network. This is consistent with previous findings where a lower number of contact points can lead to a higher 
PTC intensity due to an easier disruption of conductive pathways. Although the composites can exhibit a higher PTC intensity value at lower filler content, the subsequent NTC effect also becomes more apparent. The hypothesis here is that the increased inter-particle spacing, as a consequence of reduced filler content, allows GNP particles to exhibit more mobility in order to re-agglomerate at higher temperatures [39-41].

Conversely, CNT/HDPE composites show only a minimal gradual increase in resistivity upon heating for all filler loadings, due to the difficulty in breaking down the "robust" conductive networks formed by high aspect ratio 1D CNTs. Among all three CNT loadings, the lowest filler content ( $2 \mathrm{wt} . \% \mathrm{CNT}$ ) displays a relatively high initial resistance and a more pronounced NTC effect, due to a re-establishment of the conductive network upon heating [40, 42].

A considerable variation of PTC intensity has been observed for different filler shapes, ranging from eight orders of magnitudes, two orders of magnitude, to less than one order of magnitude, for $\mathrm{AgS}(50 \mu \mathrm{m}), \mathrm{GNP}$ and $\mathrm{CNT}$ in HDPE composites, respectively (Figure 7c). This finding can be explained from the viewpoint of how the conductive network (or contact points between fillers) behave upon heating. Comparing the conductive network for $0 \mathrm{D}, 1 \mathrm{D}$, and $2 \mathrm{D}$ fillers, it can be concluded that $0 \mathrm{D} \mathrm{AgS}$ has the least number of contact points due to their lowest specific surface area. On the other hand, 1D nanotubes, exhibiting the highest aspect ratio and largest surface areas, can form robust, entangled and interconnected networks, leading to a large number of contact points which are the least likely to be separated by thermal expansion of the polymer matrix. 2D GNPs present an intermediate case in terms of both aspect ratio and number of contact points but without the possibility of entanglements, forming a network that is partially affected by the temperature approaching the PTC switch point with a trace of associated NTC behaviour. A similar trend was found in amorphous TPU, with a reduced PTC intensity or even a predominant NTC effect alongside an increasing number of contact points 
between conductive fillers, i.e. a more robust and interconnected network when moving from 0D to 1D fillers (see SI Figure 3).
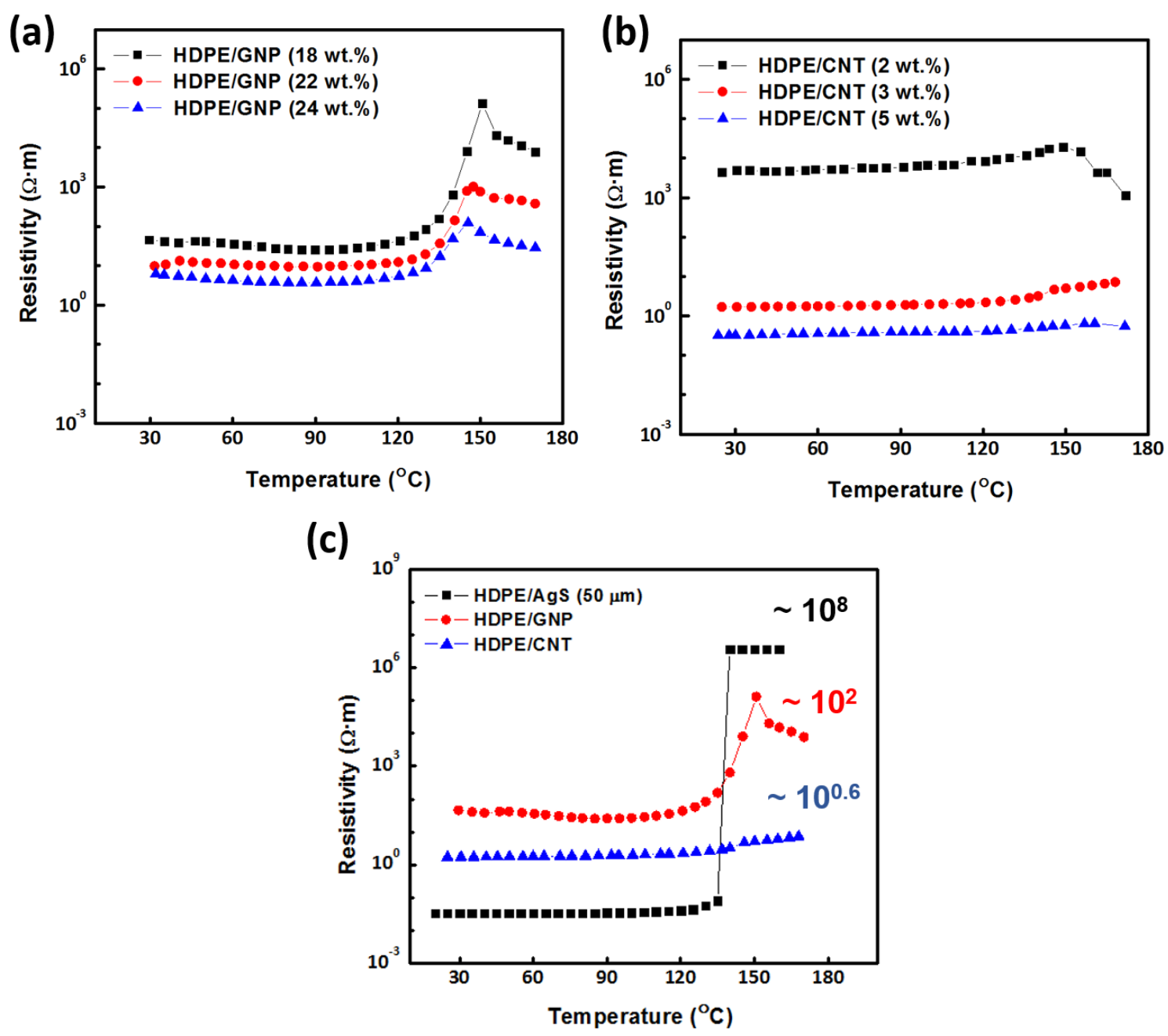

Figure 7. The pyroresistive behaviour of (a) HDPE/GNP composites (18, 22, and 24 wt.\%); (b) HDPE/CNT composites (2, 3 and 5 wt.\%). (c) A comparison between the effect of $0 D, 1 D$, and $2 D$ filler conductive networks on the pyroresistive behaviour of HDPE/AgS (50 $\mu \mathrm{m})$, HDPE/GNP and HDPE/CNT composites.

\section{Conclusions}

A systematic study into the effect of different conductive networks on pyroresistive performance of polymer composites has been reported. Three representative conductive fillers 
with distinct dimensions and shapes, in combination with three different polymer matrices were selected to form different conductive networks. A more "robust" filler conductive network results in a reduced disruption from the thermal expansion of the polymer matrix and a less pronounced (or absent) PTC effect. These "robust" filler networks can be the consequence of smaller filler size, higher aspect ratio and/or distribution of filler (due to intrinsic polymer properties such as crystallinity). Similar to the well-known percolation theory, which implies that electrical resistivity changes the most at filler loadings around the percolation threshold, the highest PTC intensity was also observed around the "critical" percolation threshold with conductive pathways established with a minimum number of contacts. Excessive "contact" points together with highly inter-connected or entangled networks as in the case of CNTs can result in no PTC or even a NTC effect upon temperature increase. This systematic study can be instrumental in providing a better understanding of the effect of the conductive network on pyroresistive behaviour of CPCs as well as the selection of the most appropriate conductive filler and polymer matrix for various applications requiring temperature and current selfregulation.

\section{Conflicts of interest}

The authors declare no conflict of interest.

\section{Acknowledgement}

The authors gratefully acknowledge the financial support from LMK Thermosafe Ltd, and Innovate UK (KTP number: KTP009619). 


\section{References}

[1] E. Bilotti, R. Zhang, H. Deng, M. Baxendale, T. Peijs, Fabrication and property prediction of conductive and strain sensing TPU/CNT nanocomposite fibres, Journal of Materials Chemistry 20(42) (2010) 9449-9455.

[2] L. Lin, S. Liu, Q. Zhang, X. Li, M. Ji, H. Deng, Q. Fu, Towards tunable sensitivity of electrical property to strain for conductive polymer composites based on thermoplastic elastomer, ACS Appl Mater Interfaces 5(12) (2013) 5815-24.

[3] K. Tian, Q. Pan, H. Deng, Q. Fu, Shear induced formation and destruction behavior of conductive networks in nickel/polyurethane composites during strain sensing, Composites Part A: Applied Science and Manufacturing 130 (2020) 105757.

[4] D. Li, E.J. Borkent, R. Nortrup, H. Moon, H. Katz, Z. Bao, Humidity effect on electrical performance of organic thin-film transistors, Applied Physics Letters 86(4) (2005) 042105-1-042105-3.

[5] T. Yokota, Y. Inoue, Y. Terakawa, J. Reeder, M. Kaltenbrunner, T. Ware, K. Yang, K. Mabuchi, T. Murakawa, M. Sekino, Ultraflexible, large-area, physiological temperature sensors for multipoint measurements, Proceedings of the National Academy of Sciences 112(47) (2015) 14533-14538.

[6] J. Jeon, H.B.R. Lee, Z. Bao, Flexible wireless temperature sensors based on Ni microparticle-filled binary polymer composites, Advanced Materials 25(6) (2013) 850-855.

[7] Y. Liu, T. van Vliet, Y. Tao, J.J. Busfield, T. Peijs, E. Bilotti, H. Zhang, Sustainable and self-regulating out-of-oven manufacturing of FRPs with integrated multifunctional capabilities, Composites Science and Technology 190 (2020) 108032.

[8] T. Villmow, S. Pegel, A. John, R. Rentenberger, P. Pötschke, Liquid sensing: smart polymer/CNT composites, Materials Today 14(7-8) (2011) 340-345.

[9] H. Zhang, E. Bilotti, T. Peijs, The use of carbon nanotubes for damage sensing and structural health monitoring in laminated composites: a review, Nanocomposites 1(4) (2015) 167-184.

[10] H. Zhang, Y. Liu, M. Kuwata, E. Bilotti, T. Peijs, Improved fracture toughness and integrated damage sensing capability by spray coated CNTs on carbon fibre prepreg, Composites Part A: Applied Science and Manufacturing 70 (2015) 102-110.

[11] S.M. Doshi, T.B. Lyness, E.T. Thostenson, Damage monitoring of adhesively bonded compositemetal hybrid joints using carbon nanotube-based sensing layer, Nanocomposites 6(1) (2020) 12-21.

[12] K. Ohe, Y. Naito, A new resistor having an anomalously large positive temperature coefficient, Japanese Journal of Applied Physics 10(1) (1971) 99.

[13] Z.D. Xiang, T. Chen, Z.M. Li, X.C. Bian, Negative temperature coefficient of resistivity in lightweight conductive carbon nanotube/polymer composites, Macromolecular Materials and Engineering 294(2) (2009) 91-95.

[14] Y. Liu, H. Zhang, H. Porwal, J.J. Busfield, T. Peijs, E. Bilotti, Pyroresistivity in conductive polymer composites: a perspective on recent advances and new applications, Polymer International 68(3) (2019) 299-305.

[15] Y. Luo, G. Wang, B. Zhang, Z. Zhang, The influence of crystalline and aggregate structure on PTC characteristic of conductive polyethylene/carbon black composite, European polymer journal 34(8) (1998) 1221-1227.

[16] H. Deng, T. Skipa, R. Zhang, D. Lellinger, E. Bilotti, I. Alig, T. Peijs, Effect of melting and crystallization on the conductive network in conductive polymer composites, Polymer 50(15) (2009) 3747-3754.

[17] J. Meyer, Glass transition temperature as a guide to selection of polymers suitable for PTC materials, Polymer Engineering \& Science 13(6) (1973) 462-468.

[18] X.-S. Yi, L. Shen, Y. Pan, Thermal volume expansion in polymeric PTC composites: a theoretical approach, Composites Science and Technology 61(7) (2001) 949-956.

[19] C. Xiong, Z. Zhou, W. Xu, H. Hu, Y. Zhang, L. Dong, Polyurethane/carbon black composites with high positive temperature coefficient and low critical transformation temperature, Carbon 43(8) (2005) 1788-1792. 
[20] J. Fournier, G. Boiteux, G. Seytre, G. Marichy, Positive temperature coefficient effect in carbon black/epoxy polymer composites, Journal of materials science letters 16(20) (1997) 1677-1679.

[21] P. Kar, B.B. Khatua, Highly reversible and repeatable PTCR characteristics of PMMA/Ag-coated glass bead composites based on CTE mismatch phenomena, Polymer Engineering \& Science 51(9) (2011) 1780-1790.

[22] T. Ota, M. Fukushima, Y. Ishigure, H. Unuma, M. Takahashi, Y. Hikichi, H. Suzuki, Control of percolation curve by filler particle shape in Cu-SBR composites, Journal of materials science letters 16(13) (1997) 1182-1183.

[23] X. Jing, W. Zhao, L. Lan, The effect of particle size on electric conducting percolation threshold in polymer/conducting particle composites, Journal of materials science letters 19(5) (2000) 377-379.

[24] H. Xu, Y. Wu, D. Yang, J. Wang, H. Xie, Study on theories and influence factors of PTC property in polymer based conductive composites, Rev. Adv. Mater. Sci 27(2) (2011) 173-183.

[25] E. Asare, J. Evans, M. Newton, T. Peijs, E. Bilotti, Effect of particle size and shape on positive temperature coefficient (PTC) of conductive polymer composites (CPC)-a model study, Materials \& Design 97 (2016) 459-463.

[26] X. Zhang, S. Zheng, H. Zou, X. Zheng, Z. Liu, W. Yang, M. Yang, Two-step positive temperature coefficient effect with favorable reproducibility achieved by specific "island-bridge" electrical conductive networks in HDPE/PVDF/CNF composite, Composites Part A: Applied Science and Manufacturing 94 (2017) 21-31.

[27] A. Bianco, H.-M. Cheng, T. Enoki, Y. Gogotsi, R.H. Hurt, N. Koratkar, T. Kyotani, M. Monthioux, C.R. Park, J.M.D. Tascon, J. Zhang, All in the graphene family - A recommended nomenclature for twodimensional carbon materials, Carbon 65 (2013) 1-6.

[28] Nanocyl ${ }^{\circledR}$ NC7000TM. http://www.nanocyl.com/wp-content/uploads/2016/07/DM-TI-02-TDSNC7000-V08.pdf. (Accessed 31/03/2020.

[29] Y. Liu, H. Zhang, H. Porwal, W. Tu, K. Wan, J. Evans, M. Newton, J.J.C. Busfield, T. Peijs, E. Bilotti, Tailored pyroresistive performance and flexibility by introducing a secondary thermoplastic elastomeric phase into graphene nanoplatelet (GNP) filled polymer composites for self-regulating heating devices, Journal of Materials Chemistry C 6(11) (2018) 2760-2768.

[30] Y. Liu, H. Zhang, H. Porwal, W. Tu, J. Evans, M. Newton, J.J. Busfield, T. Peijs, E. Bilotti, Universal Control on Pyroresistive Behavior of Flexible Self-Regulating Heating Devices, Advanced Functional Materials 27(39) (2017) 1702253.

[31] surface energy of plastics. https://www.tstar.com/blog/bid/33845/surface-energy-of-plastics. (Accessed 31/03/2020.

[32] I.M. Ward, J. Sweeney, Mechanical properties of solid polymers, John Wiley \& Sons2012.

[33] I. Krupa, I. Novák, I. Chodák, Electrically and thermally conductive polyethylene/graphite composites and their mechanical properties, Synthetic Metals 145(2) (2004) 245-252.

[34] G. Ambrosetti, I. Balberg, C. Grimaldi, Percolation-to-hopping crossover in conductor-insulator composites, Physical Review B 82(13) (2010) 134201.

[35] S. Luo, C. Wong, Study on effect of carbon black on behavior of conductive polymer composites with positive temperature coefficient, IEEE Transactions on Components and Packaging Technologies 23(1) (2000) 151-156.

[36] P.H. Kang, Y.C. Nho, The effect of carbon black on PTC characteristics of conductive polyethylene/carbon black composite, Journal of Industrial and Engineering Chemistry 7(4) (2001) 199-203.

[37] P. Poomalai, Siddaramaiah, Studies on poly (methyl methacrylate)(PMMA) and thermoplastic polyurethane (TPU) blends, Journal of Macromolecular Science Part A: Pure Applied Chemistry 42(10) (2005) 1399-1407.

[38] R.M. Santos, S.T. Mould, P. Formánek, M.C. Paiva, J.A. Covas, Effects of particle size and surface chemistry on the dispersion of graphite nanoplates in polypropylene composites, Polymers $10(2)$ (2018) 222. 
[39] E. Bilotti, H. Zhang, H. Deng, R. Zhang, Q. Fu, T. Peijs, Controlling the dynamic percolation of carbon nanotube based conductive polymer composites by addition of secondary nanofillers: The effect on electrical conductivity and tuneable sensing behaviour, Composites Science and Technology 74 (2013) 85-90.

[40] H. Zhang, E. Bilotti, W. Tu, C.Y. Lew, T. Peijs, Static and dynamic percolation of phenoxy/carbon nanotube nanocomposites, European Polymer Journal 68 (2015) 128-138.

[41] Y. Gao, O.T. Picot, H. Zhang, E. Bilotti, T. Peijs, Synergistic effects of filler size on thermal annealinginduced percolation in polylactic acid (PLA)/graphite nanoplatelet (GNP) nanocomposites, Nanocomposites 3(2) (2017) 67-75.

[42] F. Liu, X. Zhang, W. Li, J. Cheng, X. Tao, Y. Li, L. Sheng, Investigation of the electrical conductivity of HDPE composites filled with bundle-like MWNTs, Composites Part A: Applied Science and Manufacturing 40(11) (2009) 1717-1721. 